\title{
Design of a 100 MW Concentrated Solar Power Linear Fresnel plant with Molten Salt Thermal Energy Storage in Riyadh, Saudi Arabia
}

\author{
Abdullah S. Albarqi, Alberto Boretti* \\ College of Engineering, Prince Mohammad Bin Fahd University, Al Khobar, Saudi Arabia
}

Received May 6, 2020; Revised May 15, 2020; Accepted June 23, 2020

Copyright $(2020$ by authors, all rights reserved. Authors agree that this article remains permanently open access under the terms of the Creative Commons Attribution License 4.0 International License

\begin{abstract}
Our world has witnessed a rapid increase in power generation as a result of the growth of population and economy. Currently, people depend on conventional fuel energy as the main source of power generation; however, conventional fuel is well known for its limitation and impact on the environment. Thus, it was necessary to invest in an alternative source of energy such the solar power. Much research and development for solar power such as Concentrated solar power (CSP) have been implemented around the world, and it shows the capability to compete with conventional fuel technology. This paper aims to study the feasibility of constructing 100 MW CSP Linear Fresnel (LF) solar power in Riyadh, Saudi Arabia. In this study, the National Renewable Energy Laboratory (NREL) System Advisor Model (SAM) was used to design, simulate, and analyze the system. The system was designed based on CSP LF technology with molten salt thermal energy storage (TES), where TES supplies the power cycle with the required thermal energy after sunset. The result has revealed the system's capability to produce a good amount of solar power most of the year, reaching up to 38 GWh during summer. The LF system shows a good capacity factor (CF) exceeding $40 \%$. The study shows that Saudi Arabia is a good place to install the CSP LF solar plant.
\end{abstract}

Keywords Concentrated Solar Power, Thermal Energy Storage, Linear Fresnel, Riyadh, Saudi Arabia

\section{Nomenclature}
$\mathrm{AC}$
Alternating current
CF Capacity factor
CSP Concentrating solar power

$\begin{array}{ll}\text { DC } & \text { Direct current } \\ \text { DNI } & \text { Direct normal irradiance } \\ \text { GASTAT } & \text { General Authority of Statistic } \\ \text { HTF } & \text { Heat transfer fluid } \\ \text { LCOE } & \text { Levelized cost of electricity } \\ \text { LF } & \text { Linear Fresnel } \\ \text { NREL } & \text { National Renewable Energy Lab } \\ \text { PT } & \text { Parabolic trough } \\ \text { SAM } & \text { System Advisor Model } \\ \text { ST } & \text { Solar tower } \\ \text { TES } & \text { Thermal energy storage } \\ \text { PV } & \text { Photovoltaics }\end{array}$

\section{Introduction}

In the last few decades, the world has witnessed a swift change in demography and economy due to the rapid development in the technology. Nowadays, many rural areas became similar to urban areas in terms of electricity utilization and the use of communication technologies. As a result of this change, the demand for energy has increased all over the world [1]. Currently, conventional energy sources like fossil fuels, coal, and nuclear power are dominating the vast energy market. However, conventional energy is well known for its limitation and massive impact on human health and global emissions [2]. Thus, it was necessary to look for an environmentally friendly source of energy that is sustainable and renewable to insure having a continuous supply of energy to meet the increasing demands.

Solar power is considered as one of the most promising and reliable sources of energy. Moreover, due to its abundance, solar power is seen as a sustainable and renewable source of electrical power [3]. The sun energy is converted into electrical power either by direct conversion of the sunlight into electricity using Photovoltaics (PV), or 
indirectly using concentrating solar power (CSP) [4]. In the PV solar system, the solar cells made of semiconductor materials convert the sunlight into electrical DC. The current can be used directly or converted into AC using an inverter or set of inverters for grid connection [5]. On the other hand, the CSP system uses lenses or mirrors to track the sunlight and direct the massive amount of the solar thermal energy on a small area containing heat transfer fluid (HTF) to generate superheated steam used in steam turbine power cycle [6], [7].

Solar power technology has experienced rapid development over the past few decades, which led to improving its efficiency and cost. This led to increasing the annual growth rate for the last ten years by $48 \%$ [8]. Currently, the global capacity of solar power has reached up to $400 \mathrm{GW}$, and it counts for around $7 \%$ of worldwide electricity production. Soon, the number of solar power plants around the world is expected to rapidly increase due to the higher demand for electricity, the low cost of solar power, and the concerns global effect coming from burning the conventional fuel.

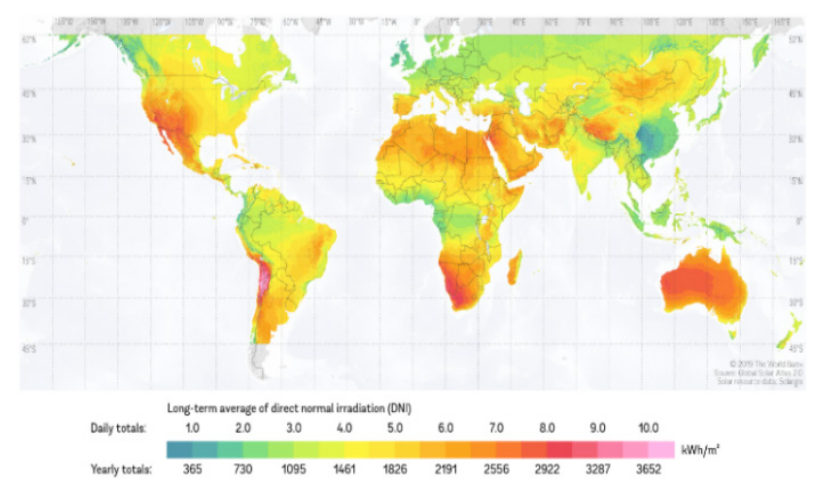

Figure 1. Global direct normal irradiation [9]. Credit Solargis

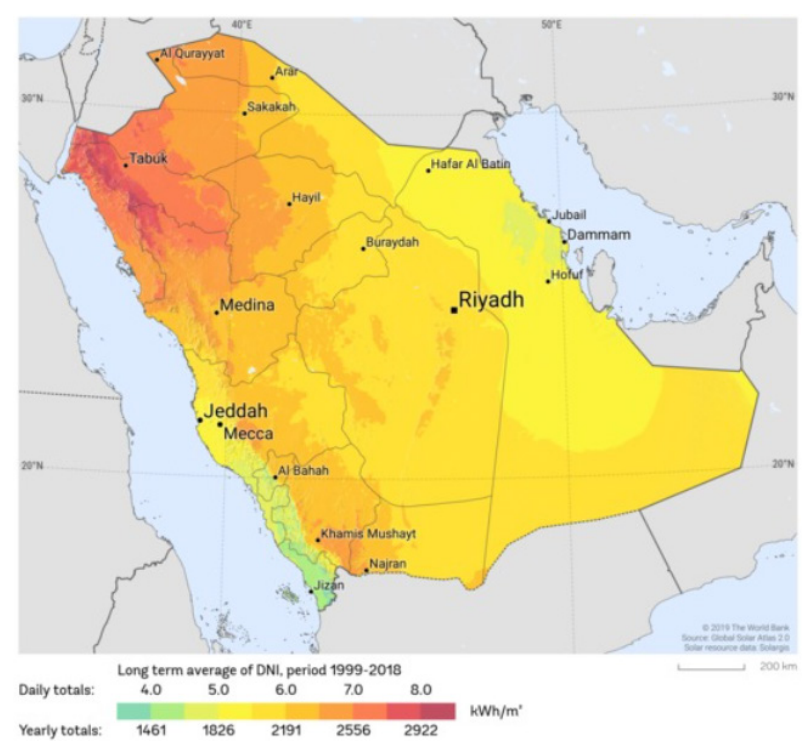

Figure 2. Direct normal radiation for Saudi Arabia [11]. Credit Solargis

Saudi Arabia has the potential to produce solar power on a large scale due to its location on the global sunbelt. Figure 1 (from [9]) shows the intensity of the solar irradiation around the world, and it shows that Saudi Arabia is among the highest receiver of the direct normal irradiance (DNI).

According to the GASTAT 2018 report [10], Saudi Arabia has an average of $5,366 \mathrm{Wh} / \mathrm{m}^{2}$ daily levels of DNI, exceeding the minimum threshold required for the CSP system $\left(4,960 \mathrm{Wh} / \mathrm{m}^{2}\right)$. Also, the DNI can reach up to 7,750 $\mathrm{Wh} / \mathrm{m}^{2}$ in a city like Tabuk in the northern region of Saudi Arabia. Figure 2 is the map of solar resource for Saudi Arabia from [11]

Moreover, Saudi Arabia has a wide landscape with year-round clear skies which make it an excellent location for solar power generation [12]. Though, some challenges are existing in some areas in Saudi Arabia due to their geomorphological features. One of the main challenges that would affect the performance of the solar power system in Saudi Arabia is dust and sand. The accumulated dust over the solar panels or collectors affects the amount of converted solar energy which requires regular cleaning to recover the design efficiency of the solar system. The elevated temperature is another problem that affects the solar system performance especially for the PV system [12]. However, the high temperature can be an advantage in the case of the CSP system. Such challenges can be reduced by adapting the glasshouses technology to minimize the effect of the dust. Also, adapting the CSP technology can be a good choice for Saudi Arabia due to the advantage of the high temperature.

Currently, Saudi Arabia has a very low utilization of solar power comparing to the leading countries such as the USA, China, or Spain. As per [10], the amount of electricity produced by solar power in Saudi Arabia was less than $0.004 \%$ of the total electrical capacity in 2018 . However, with Saudi's new vision 2030, Saudi Arabia plans to expand the solar power utilization to reach $10 \%$ of total energy production by 2023 [10].

The CSP system is built based on the Rankine cycle principle. The main component of the CSP power cycle is the solar filed and the Rankine steam turbine cycle, and in some applications, the thermal energy storage (TES) is used [7]. The typical process of a CSP system is shown in [13].

Although the CSP is counted for less than $2 \%$ of the total electrical capacity produced by solar power, the CSP has an advantage over the PV system due to the capability to store energy using a TES technology. The TES systems usually operated with oil or molten salt as HTF to store generated thermal energy and dispatch it during the night. This advantage of the TES system makes the CSP more competitive with the conventional power system such as fossil fuels and nuclear power.

CSP technologies are widely used in many countries around the world. And the main four proven CSP technologies are the parabolic trough (PT), solar tower 
(ST), linear Fresnel (LF), and solar dish. Compared to the CSP technologies, the LF is seen as a promising technology due to low investment cost, less land required, low Levelized cost of electricity (LCOE), low-cost collector and easer maintenance, [13], [14] and [15]. The CSP LF uses a set of reflecting mirrors to direct the sunlight to the receiver. Compared to the PT, the LF has fewer absorber connections which reduce the heat losses. Also, the control of the heat flux in LF is easier than the one for ST due to the distance between the reflectors and receiver [15].

Figure 3 shows the relation between the reflecting mirrors and the receiver tube. The reflectors are oriented in transversal and longitudinal plane's angles to direct the sunlight toward the receiver tube.

In this paper, we analyze CSP LF with molten-salt thermal storage by using the System Advisory Model (SAM) code. This computation tends to study the feasibility of building a $100 \mathrm{MW}$ solar power system based on the LF technology in Saudi Arabia to support the electrical system in Riyadh city.

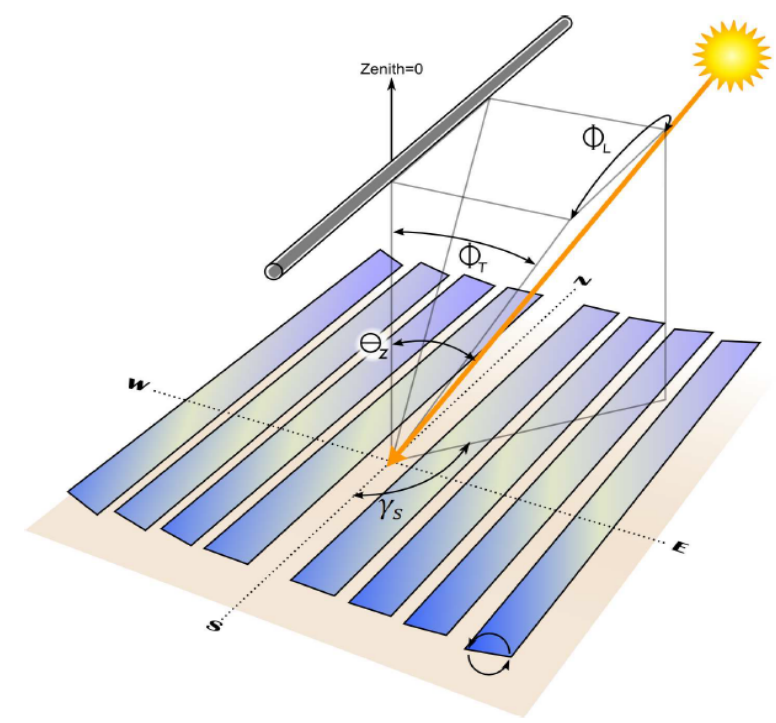

Figure 3. Linear Fresnel optical performance from [14]. Credit NREL

\section{Materials and Methods}

CSP LF model is analysed using the System Advisory Model (SAM). SAM's model is free software developed by the National Renewable Energy Laboratory (NREL), and it gives a prediction for the performance of different renewable energy systems [16]. The model provides estimation for the annual energy production and financial cost of the constructed solar power system. For the CSP cycle, SAM's model calculates the cycle performance-based based on the Rankine cycle [17]. The software allows the users to control the input variables for the cycle's subsystem including the solar field, power cycle, thermal storage, system auxiliary, and corresponding cost and financial parameters [18]. As the solar power plant performance depends upon the site parameters, SAM offers access for thousands of weather files through the National Solar Radiation Database (NSRDB) and another international free database. The weather file contains year-round hourly data that allow SAM to do annual simulation consisting of a series of steady-state hourly regression calculation. The detailed calculation allows SAM to capture the transient effects during the start-up and shutdown, and the thermal inertial associated with the system which will help the users to adjust the system response during the warmup and cool down stages [17]. In general, the model is considered fast, flexible and accurate tools for most conventional CSP power cycles [18].

Like other CSP systems, SAM's molten salt LF model represents all indirect solar subsystems such as the solar filed, steam Rankine power cycles, heat rejection system, feedwater pumps, plant control system, and optional thermal energy storage and auxiliary fossil backup systems. For the sake of brevity, we will discuss the four mains competent of the system, solar field, collector and receiver, power cycle, and thermal energy storage.

The solar field is the area that contained the solar radiation collecting modules and associated complements such as the absorber tubes and piping. The solar field is the initial parameter for designing the CSP LF system, and it is essential to predict the total thermal energy output of the system. SAM calculates the area required for the solar field as in eq. (1). Also, the solar field thermal output is calculated according to the desired power cycles and the variable solar resource as in eq. (2) [19].

$$
A_{s f, \text { tot (acres) }}=A_{s f, \text { tot }\left(m^{2}\right)} * \frac{L_{\text {row spacing }}}{\max \left[W_{S C A, i}\right]} * 0.00027471
$$

$\boldsymbol{A}_{\text {sf,tot }}$ : Solar field area (acres)

$\boldsymbol{L}_{\text {row spacing }}$ : length of row spacing $(\mathrm{m})$

$W_{S C A, i}:$ Aperture width of each collector in the loop (m)

$$
Q_{s f, d e s}=S M * \frac{W_{\text {des, gross }}}{\eta_{p b, \text { des }}}
$$

$\boldsymbol{Q}_{\boldsymbol{s f}, \text { des }}$ : Solar field design heat output (MW)

SM : Solar Multiple

$W_{\text {des,gross }}$ : Design gross power output (MW)

$\boldsymbol{\eta}_{\boldsymbol{p} b, \text { des }}$ : design power block efficiency

The collector's reflective area, optical efficiency and the value of DNI are the main factors determineing the amount of total thermal energy incident on the receiver. In the case of the CSP LF, the collector consists of a set of long reflective mirrors that are arranged parallel with the North-South axis and adjusted to reflect the sunlight toward a linear receiver [14]. Thus, the optical performance of the collector merely depends on the longitudinal plane incidence angle $\Phi L$ and transversal plane incidence angles $\Phi T$ for each reflective mirror as illustrated in figure [4]. 
The LF optical efficiency is calculated using eq. (3).

$$
\eta_{\text {optical }}=\frac{Q_{\text {tot }, \text { receiver }}}{D N I * A_{\text {act }, \text { Aperture }}}
$$

$\boldsymbol{\eta}_{\text {optical }}:$ Optical efficiency

$\boldsymbol{Q}_{\text {totreceiver }}:$ Receiver total thermal energy (MW)

DNI : Direct normal irradiance $\left(\mathrm{MW} / \mathrm{m}^{2}\right)$

$\boldsymbol{A}_{\text {act,Aperture }}$ : Actual aperture area $\left(\mathrm{m}^{2}\right)$

The power cycle is built based on a steam Rankine cycle. The function of the power cycle is to convert thermal energy to electric energy. In the CSP LF SAM model, the power cycle consists of the superheated two-stage turbine with multiple extractions for feed water heating and a reheat extraction between the high pressure and low-pressure turbine stages. The LF power cycle performance is a function of steam inlet temperature, mass flow rate, and ambient temperature [19]. And the final power output and net power output for the power cycle are defined by eq. (4) and (5) respectively [16].

$$
\dot{W}_{c y c l e}=\eta_{c y c l e, r e f} f_{p b, T} f_{p b, l o a d} \dot{Q}_{p b}
$$

$\dot{\boldsymbol{W}}_{\text {cycle }}$ : Cycle power output (MW)

$\boldsymbol{\eta}_{\text {cycle,ref }}:$ Reference efficiency

$\boldsymbol{f}_{\boldsymbol{p} \boldsymbol{b}, \boldsymbol{T}}:$ Temperature-based adjustment factor

$\boldsymbol{f}_{\boldsymbol{p} \boldsymbol{b}, \text { load }}$ : Load-based adjustment factor

$\dot{\boldsymbol{Q}}_{\boldsymbol{p} \boldsymbol{b}}$ : Power block thermal energy (MW)

$\dot{W}_{\text {net }}=\dot{W}_{c y c l e}-\dot{W}_{\text {par,fixed }}-\dot{W}_{\text {par,var }}\left(T_{\text {amb, }} \frac{\dot{W}_{\text {cycle }}}{\dot{W}_{\text {cycle,des }}}\right)$

$\dot{\boldsymbol{W}}_{\text {net }}$ : Final net power output (MW)

$\dot{W}_{\text {par,fixed }}$ : Fixed parasitic loss of total plant gross power output (MW)

$\dot{\boldsymbol{W}}_{\text {par,var }}$ : Variable parasitic loss of actual power production (MW)

$\boldsymbol{T}_{\boldsymbol{a m b}}:$ : Ambient temperature (K)

Also, the LF power cycle model offers auxiliary fossil backup boiler in parallel with the power cycle. In the minimum backup mode, the auxiliary boiler supplies heat to the HIF to compensate for the drop in the solar field output. And, the amount of dispatched heat by the auxiliary boiler is defined by eq. (6) [17]. Moreover, the model offers a cooling system condenser for heat rejection. And in our case, we are using an air-cooled condenser for our model.

$$
\begin{gathered}
\dot{q}_{a u x}=\dot{q}_{p b, \text { des }} \cdot f_{\text {tod }}-\dot{q}_{s f} \text { if } \dot{q}_{s f}<\dot{q}_{p b, \text { des }} \cdot f_{\text {tod }} \\
\dot{q}_{a u x}=0 \text { if } \dot{q}_{s f} \geq \dot{q}_{p b, \text { des }} \cdot f_{\text {tod }}
\end{gathered}
$$

$\dot{\boldsymbol{q}}_{\text {aux }}$ : Dispatching auxiliary heat (MW)

$\dot{\boldsymbol{q}}_{\text {pb,des }}$ : Design-point thermal load of the power block

(MW) $\dot{\boldsymbol{q}}_{s f}$ : Thermal energy produced by the solar field during the current time step (MW)

$\boldsymbol{f}_{\text {tod }}$ : TOD factor during the current time step

The TES stores access heat during the daytime to drive the power cycle during periods of low or no sunlight. The TES consists of one or more storage tank pairs integrated with the power cycle. Each pair has a hot tank to store heat from the solar field, and a cold tank to store the cold fluid coming from the power cycle. The TES is classified into two types, direct and indirect storage systems. In the direct storage system, the HTF serves as the storage medium, wherein the indirect system, a separate heating fluid with heat exchanger is required to heat-up stored fluid. The capacity of the TES is expressed by the number of hours, it can deliver thermal energy to the power cycle, and it's expressed by eq. (7) [19].

$$
C=\frac{\dot{W}_{\text {des, gross }}}{\eta_{\text {des }}} * t_{\text {full load }}
$$

$$
\boldsymbol{C}: \text { TES thermal capacity (MWh) }
$$

$\boldsymbol{t}_{\text {full load }}:$ Number of full-load hours of thermal storage (h) $\dot{W}_{\text {des,gross }}$ : Gross power output (MW)

Riyadh city was selected to be our location to study the CSP LF solar plant. Riyadh is the capital of Saudi Arabia and its largest city with a population of $8,002,100$ people (GASTAT, 2016). Similar to other locations in Saudi Arabia, Riyadh has a high potential to produce solar power on a large scale. As per [10], the average direct normal irradiance, DNI, in the Riyadh region is around 5,250 $\mathrm{Wh} / \mathrm{m}^{2}$ in 2018. The sunshine in Riyadh reached its peak in June with an average of 10.9 hours a day, and it decreases up to 6.9 hours in January and December. Also, the average day temperature reaches up to $43.5^{\circ} \mathrm{C}$ during the summer and $20.2^{\circ} \mathrm{C}$ during the wintertime [20].

The selected location for building the CSP LF solar plant is on the Eastern side of Riyadh city. It's located $10 \mathrm{Km}$ Northern side of Riyadh 's Ninth power station as shown in figure 4. The weather data for this location was taken from NREL recommended free websites for Europe, Africa, Central Asia, Southeast Asia named Photovoltaic Geographical Information System (PVGIS). The weather data provide detailed information such as the geographical location, DNI, the ambient temperature, and wind speed. Table 1 shows detailed information about the site location and specifications. All the model's details are shown in the Appendix. These parameters are the best practice for this kind of plant. The optimization is carried out to achieve the minimum LCOE by changing the size of the solar field. 


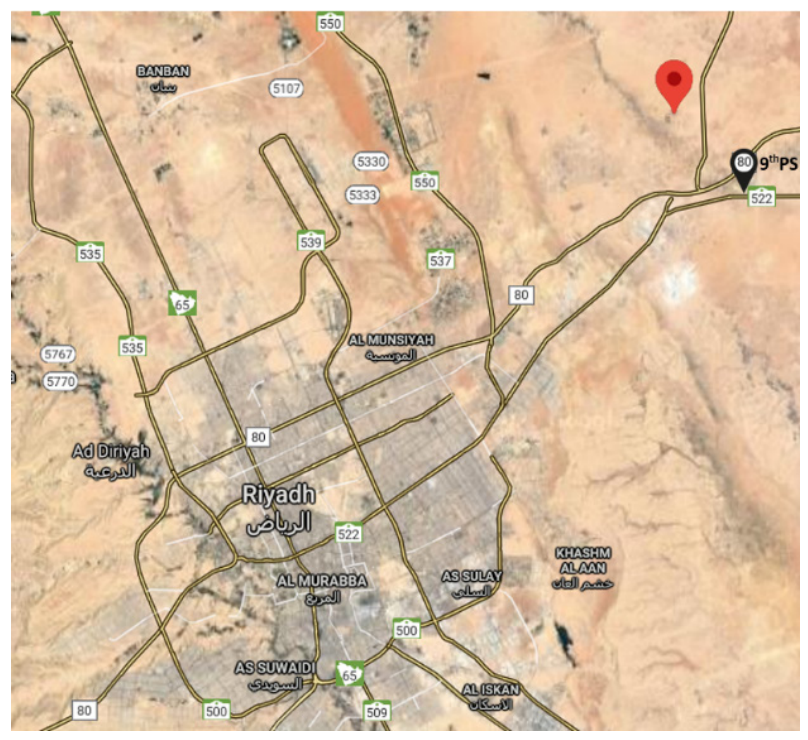

Figure 4. Suggested location of the solar power plant at Riyadh, KSA. Image reproduced modified from Google Map.

Table 1. Site's geographical location and specification

\begin{tabular}{c|c}
\hline City & Riyadh \\
\hline Elevation & 587 meters \\
Latitude & $25^{\circ} 00^{\prime} 00.0^{\prime \prime} \mathrm{N}$ \\
Longitude & $47^{\circ} 00^{\prime} 00.0^{\prime \prime} \mathrm{E}$ \\
Annual DNI & $6.40 \mathrm{kWh} / \mathrm{m}^{2} /$ day \\
Average temperature & $26.5^{\circ} \mathrm{C}$ \\
Average wind speed & $3.9 \mathrm{~m} / \mathrm{s}$ \\
\hline
\end{tabular}

\section{Results}

The CSP LF system simulation was conducted based on the Riyadh city climate. The climate data includes solar irradiance (global horizontal irradiance, GHI; direct normal irradiance, DNI, and diffuse horizontal irradiance, DHI), ambient temperature wind speed, atmospheric pressure, sun angle, and solar azimuth angle for the complete year. Table 2 presents a summary of plant and resource parameters over a year.

One of the critical parameters that have a major influence on the CSP solar system performance is the DNI. Figure 5 shows an hourly basis GHI in the blue trend for the selected solar plant location, and the second figure shows the DNI. As per the below figure, the solar irradiance has exceeded $800 \mathrm{~W} / \mathrm{m}^{2}$ for both GHI and DNI. Also, it's almost constant for the year-round due to the typical weather condition of Riyadh.

Moreover, the dry bulb and wet bulb temperature for the location are illustrated in figure 6. The dry bulb temperature is the parameter to consider for an air-cooled condenser. The wet-bulb temperature plays a role in an evaporative condenser. This later condenser offers better performances but at the cost of water usage. Also, it's seen that the increase in temperature does not have much impact on the wet-bulb temperature which will positively improve the system efficiency, especially during the summertime.

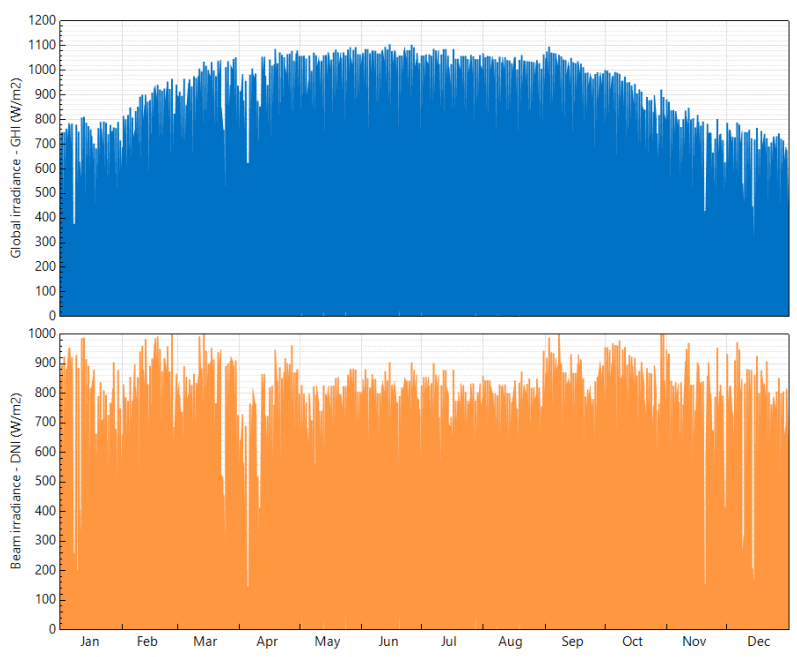

Figure 5. GHI and DHI irradiances in Riyadh.

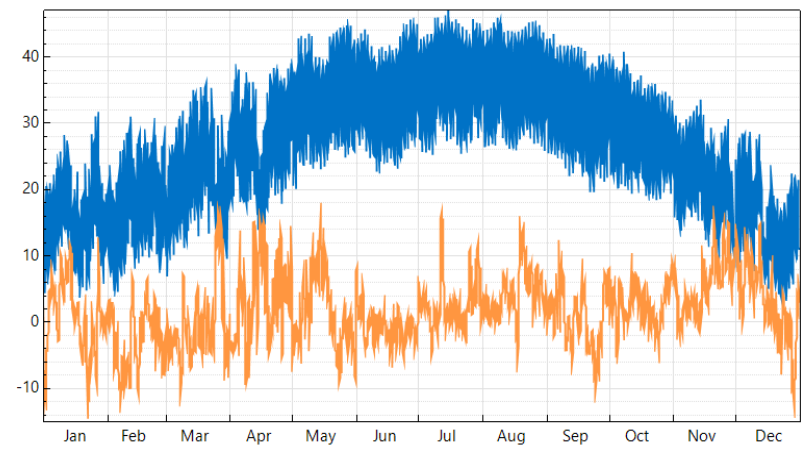

Figure 6. Dry and wet bulb temperature in Riyadh.

The heat map of the hourly beam irradiance $\left(\mathrm{w} / \mathrm{m}^{2}\right)$ incident on LF collectors (reflectors) is shown in figure 7. The amount of incident solar radiation varies from summer to winter. The maximum collected energy from solar radiation is in July and August, and it can extend up to 11 hours. While it reaches a minimum in January and December with 7-hours average exposure. The effectiveness of this solar radiation is presented by the collector optical efficiency figure 8 .

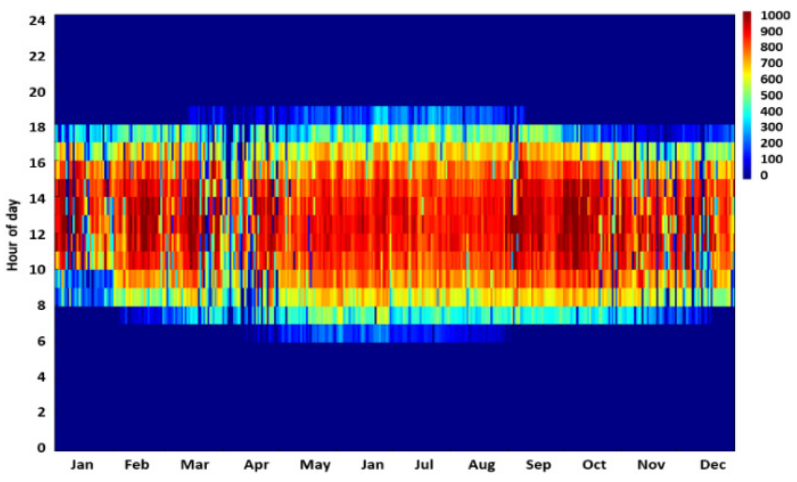

Figure 7. Heat map of beam irradiance (DNI) 


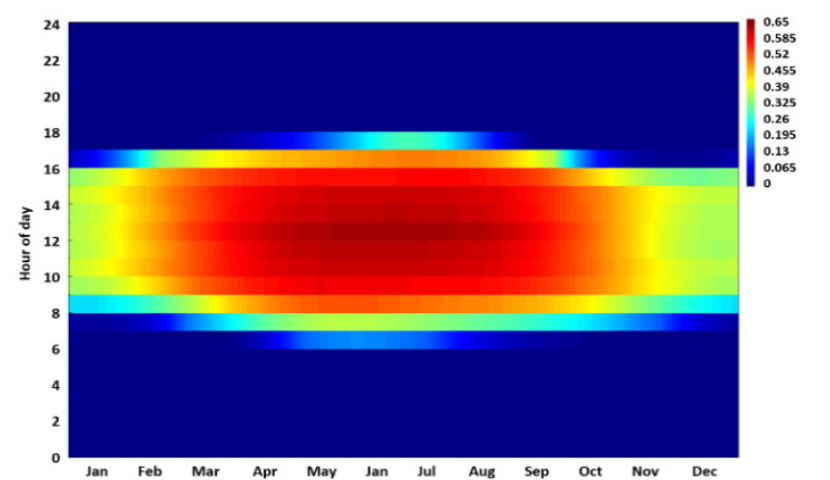

Figure 8. Field collector optical efficiency

The simulation was performed for a CSP LF system with a molten salt thermal storage. The system was evaluated based on the best higher CF, minimum LCOE, and running for 30 years of life service. Also, several experiments were performed altering the solar field aperture parameter. The simulation shows that the system has its best operating and financial performance at a solar field of $1.350 \mathrm{Km}^{2}$.

Figures 9 and 10 show a correlation between the size of the solar field aperture, CF, and LCOE. The figure shows that the $\mathrm{CF}$ of the solar plant increases as the solar filed size increases. However, enlarging the solar field is not always financially feasible. It reaches a point where the cost of energy production is inversely increasing as shown in figure 10. The simulation shows that the system has optimum performance at $41.6 \% \quad \mathrm{CF}$ and 11.73 US\$ cents/KWh LCOE respectively. And, it will yield around $364,594,880 \mathrm{kWh}$ of annual energy per year.

The monthly energy generation is illustrated in figure 11 . The maximum generated energy was during the summertime from May up to August, and it exceeded $38 \mathrm{GWh}$ per month. And, the minimum generated energy was in January, and it was round $17.5 \mathrm{GWh}$.

Also, figure 12 presents the hourly data on the average day of every month. It shows plant performance considering the cycle electrical power output, field thermal power produced, and TES thermal energy into storage. It's seen that the system stores a good amount of thermal energy, especially during the summer. It exceeded the 200MWt from May up to September. This amount of stored energy gives the system the ability to run the power cycle from 5-6 hours at nighttime. It also helps extend electrical production beyond 15 hours during summer. The lowest thermal and electrical energy production are in January and December during the winter season. It's justified since CSP solar power is best to operate during the summer when solar irradiance at its peak and the sky is clear. Also, the unexpected reduction was noticed in April, which can be a result of the dusty weather during the transition period from winter to summer.

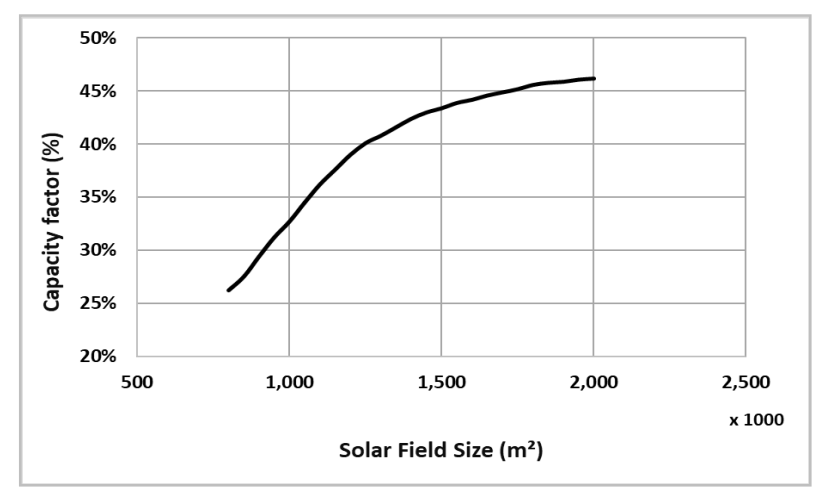

Figure 9. Solar field CF vs. field size.

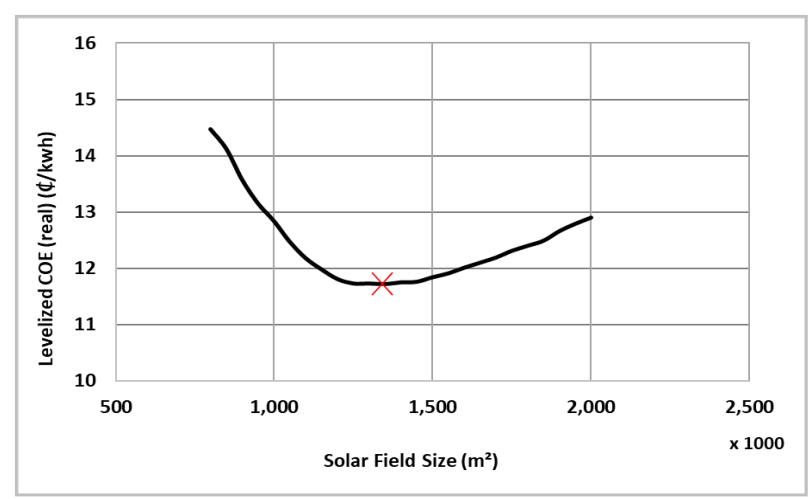

Figure 10. Solar LCOE vs. field size.

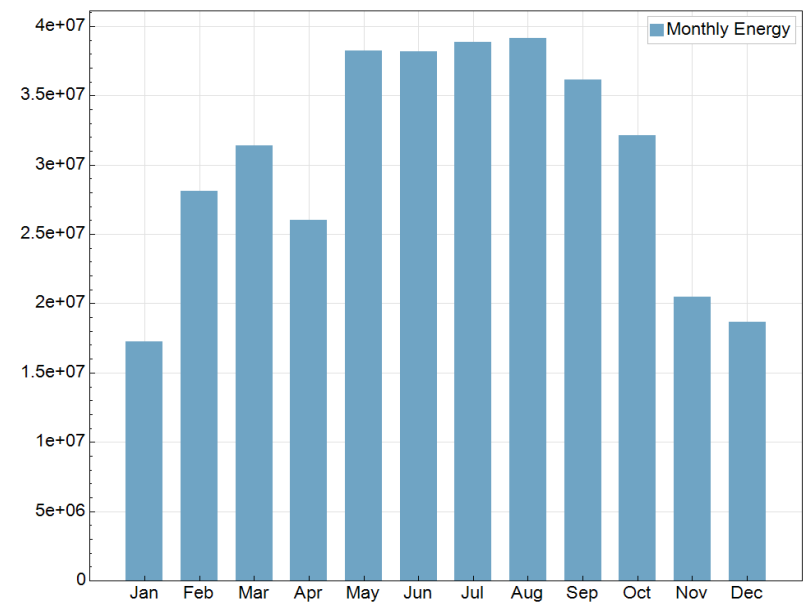

Figure 11. CSP LF monthly energy generation 

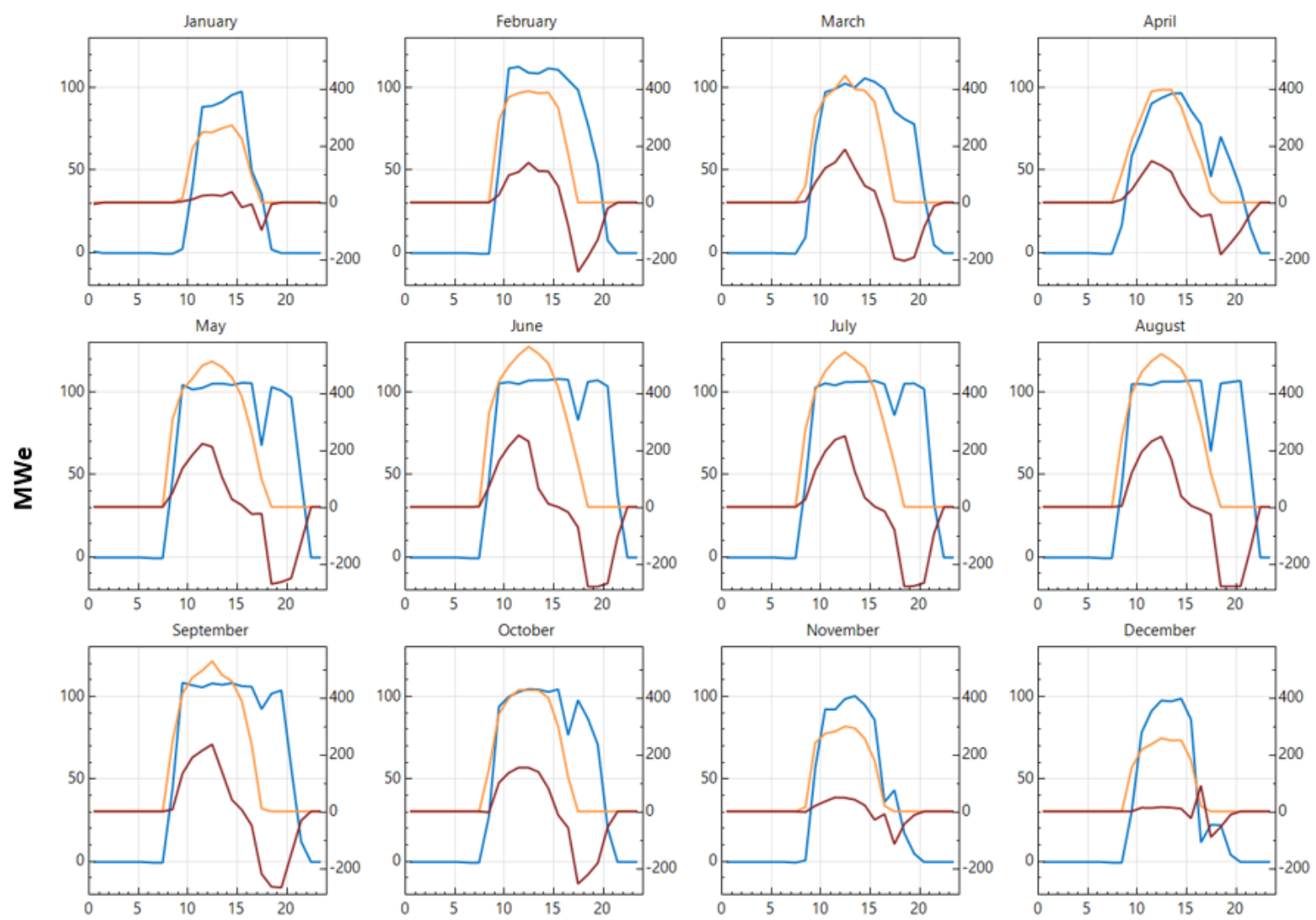

Cycle Electrical Power Output (net) (MWe)

Field Thermal Power Produced (MWt)

TES Thermal Energy into Storage (MWt)

Figure 12. Average month hourly data for electrical power output, thermal power produced, and TES.

Table 2. Plant and resource parameters over a year.

\begin{tabular}{|c|c|c|c|c|c|c|}
\hline Month & $\begin{array}{c}\text { Monthly } \\
\text { energy } \\
(\mathrm{kWh})\end{array}$ & $\begin{array}{c}\text { Monthly } \\
\text { average } \\
\text { capacity } \\
\text { factor }\end{array}$ & $\begin{array}{c}\text { Monthly average } \\
\text { Global irradiance - } \\
\text { GHI (W/m2) }\end{array}$ & $\begin{array}{c}\text { Monthly average } \\
\text { Beam irradiance - } \\
\text { DNI (W/m2) }\end{array}$ & $\begin{array}{c}\text { Monthly average } \\
\text { Diffuse irradiance - } \\
\text { DHI (W/m2) }\end{array}$ & $\begin{array}{c}\text { Monthly average } \\
\text { Dry bulb temp } \\
\left({ }^{\circ} \mathrm{C}\right)\end{array}$ \\
\hline jan & $1.80 \mathrm{E}+07$ & $24.26 \%$ & 178.43 & 202.01 & 69.00 & 15.37 \\
\hline feb & $2.91 \mathrm{E}+07$ & $43.32 \%$ & 234.72 & 276.09 & 69.64 & 17.33 \\
\hline mar & $3.22 \mathrm{E}+07$ & $43.21 \%$ & 265.31 & 260.66 & 89.59 & 21.53 \\
\hline apr & $2.66 \mathrm{E}+07$ & $36.93 \%$ & 264.42 & 204.78 & 109.30 & 26.81 \\
\hline may & $3.85 \mathrm{E}+07$ & $51.78 \%$ & 324.15 & 290.61 & 106.11 & 33.56 \\
\hline jun & $3.83 \mathrm{E}+07$ & $53.22 \%$ & 339.76 & 316.18 & 101.51 & 34.12 \\
\hline jul & $3.91 \mathrm{E}+07$ & $52.57 \%$ & 330.79 & 303.10 & 102.56 & 36.35 \\
\hline aug & $3.93 \mathrm{E}+07$ & $52.82 \%$ & 316.67 & 304.21 & 93.87 & 36.14 \\
\hline sep & $3.64 \mathrm{E}+07$ & $50.51 \%$ & 295.24 & 305.97 & 82.65 & 32.06 \\
\hline oct & $3.29 \mathrm{E}+07$ & $44.22 \%$ & 249.35 & 284.54 & 70.33 & 28.40 \\
\hline nov & $2.14 \mathrm{E}+07$ & $29.67 \%$ & 190.86 & 227.67 & 64.99 & 21.24 \\
\hline dec & $1.94 \mathrm{E}+07$ & $26.08 \%$ & 173.12 & 223.00 & 60.63 & 14.51 \\
\hline average & $3.09 \mathrm{E}+07$ & $42.38 \%$ & 263.57 & 266.57 & 85.01 & 26.45 \\
\hline
\end{tabular}




\section{Conclusions}

The concentrated solar power (CSP) linear Fresnel (LF) model has been successfully validated as one of the solar thermal energy technologies across the world. Compared to other CSP technologies, the CSP LF is more efficient due to its ability to reflect more solar energy within the same amount of space. This paper has discussed the design and performance simulation of 100 MW CSP LF with a molten salt Thermal Energy Storage (TES) using National Renewable Energy Laboratory (NREL) System Advisor Model (SAM) software. Riyadh city was selected for the simulation due to its geographical location, high population, and a high amount of solar irradiance. The result revealed a high potential to produce a good amount of thermal energy to operate the power cycle. The system shows the capability to generate enough solar energy exceeding 25 $\mathrm{GWh}$ for most of the year, and it exceeds $38 \mathrm{GWh}$ from May to August. Also, the model shows that the system is capable to produce enough thermal capacity to run the power cycle for most of the year. The TES can run for 3 hours in winter, and it can extend up to 6 hours during the summer. Also, the capacity factor (CF) has exceeded $43 \%$, which makes it very appealing when it is compared to other renewable sources of energy such as wind or solar photovoltaic. The Levelized cost of electricity (LCOE) is still high compared to conventional power cost in Saudi Arabia; however, the development of such system across Saudi Arabia will be a major milestone toward the 2030 vision of Saudi Arabia, as it will help reduce the amount of fossil fuel used at the moment to generate the electrical power.

\section{Acknowledgements}

This activity has been performed as a supervised activity during the course of Advanced Heath Transfer. AB designed and supervised the activity also providing the baseline model. ASA performed the specific simulations and wrote the draft of the paper. Both authors contributed to the final version of the manuscript.

\section{Appendix - Model details}

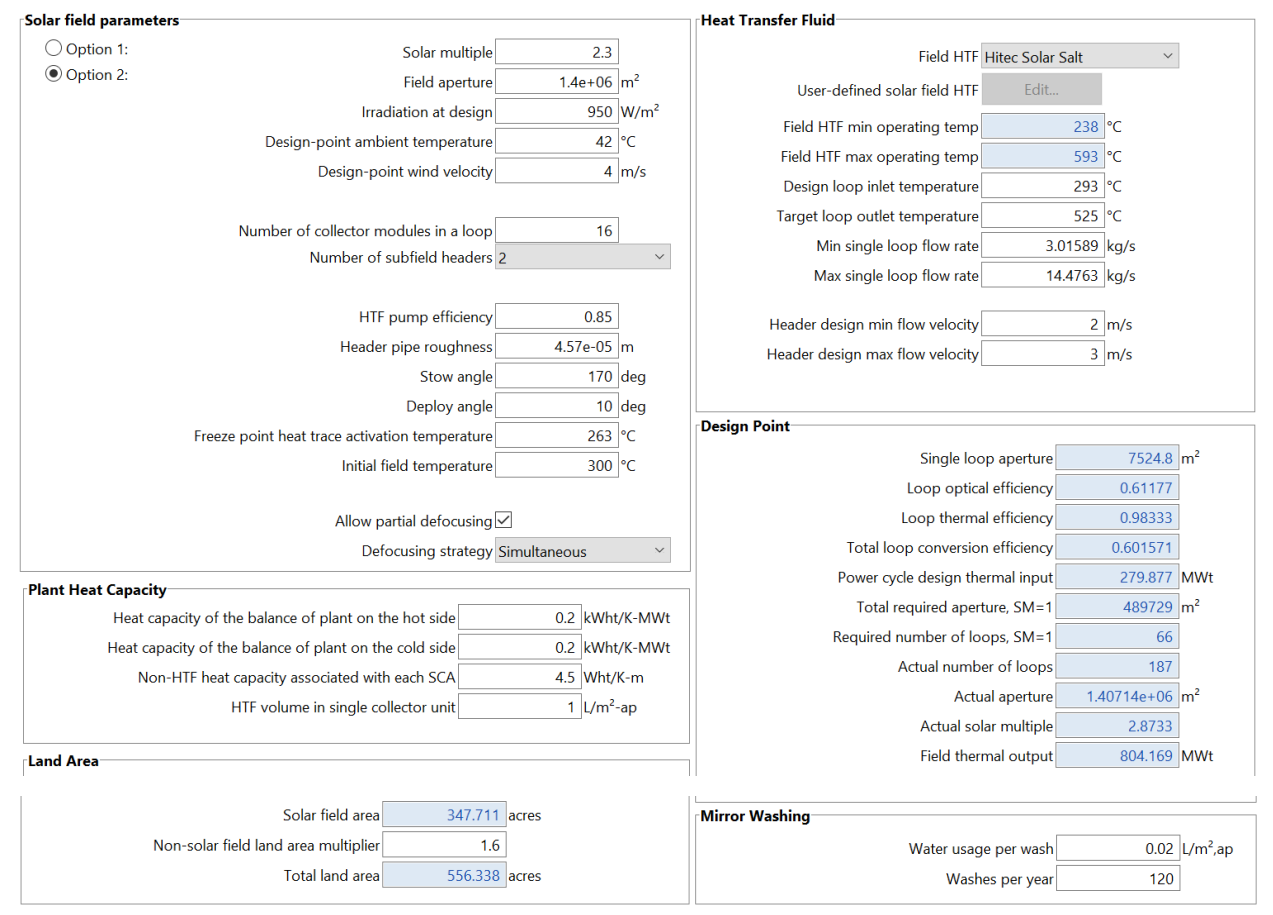

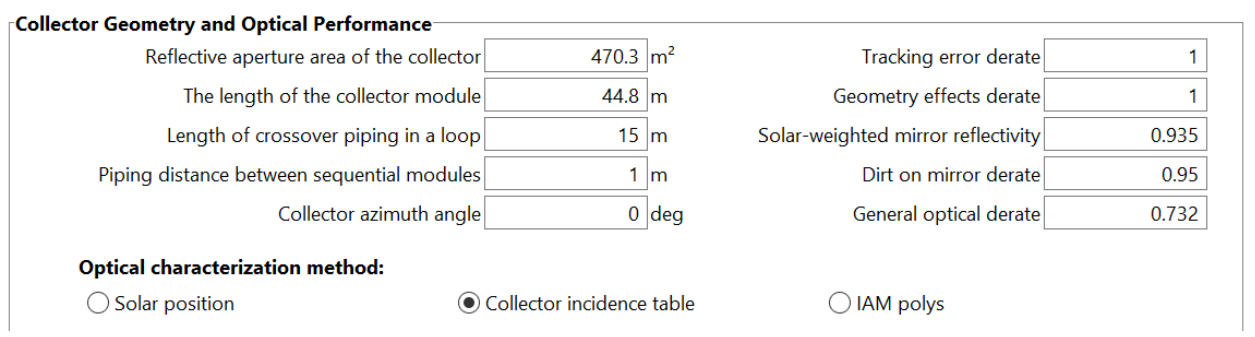


Design of a 100 MW Concentrated Solar Power Linear Fresnel plant with Molten Salt Thermal Energy Storage in Riyadh, Saudi Arabia

Solar Position/Collector Incidence Angle Table

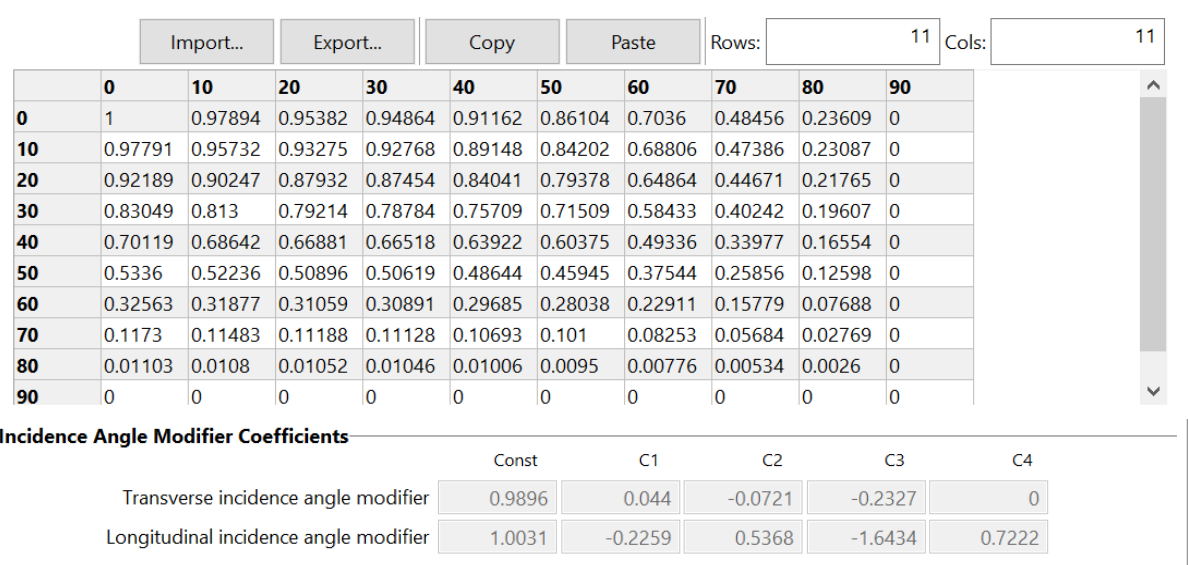

\begin{tabular}{|r|r|r|} 
Aggregate Weighted Losses & Average field temp difference at design \\
& Heat loss at design \\
Receiver thermal derate & 166.25 \\
Receiver optical derate & 0.98333 \\
\hline Collector optical loss at normal incidence & 0.940896 \\
\hline
\end{tabular}

$\begin{aligned} & \text { Receiver Geometry and Heat Loss } \\ & \text { Receiver model type }\end{aligned}$
-Polynomial fit heat loss model
HTF temperature adjustment

Plant Capacity

\begin{tabular}{r|r} 
Reference output electric power at design condition & 111.111 \\
& MWe \\
Estimated gross to net conversion factor & 0.9 \\
Estimated net output at design (nameplate) & 100.00 \\
& MWe
\end{tabular}

Parasitic losses typically reduce net output to approximately $90 \%$ of design gross power

\section{Availability and Curtailment}

Curtailment and availability losses reduce the system output to represent system outages or other events.

\begin{tabular}{|c|c|c|c|}
\hline Power Block Design Point & & & \\
\hline Rated cycle conversion efficiency & 0.397 & & \\
\hline Reference HTF outlet temperature at design & 525 & ${ }^{\circ} \mathrm{C}$ & \\
\hline Reference HTF inlet temperature at design & 293 & ${ }^{\circ} \mathrm{C}$ & \\
\hline Cycle design HTF mass flow rate & 797.1 & $\mathrm{~kg} / \mathrm{s}$ & \\
\hline Fossil backup boiler LHV efficiency & 0.9 & & \\
\hline Aux heater outlet set temp & 525 & ]$^{\circ} \mathrm{C}$ & \\
\hline Fossil backup mode & Minimum backup & level & $\checkmark$ \\
\hline
\end{tabular}




\begin{tabular}{|c|c|c|}
\hline \multicolumn{3}{|l|}{ Plant Control } \\
\hline Low resource standby period & & $\mathrm{hr}$ \\
\hline Fraction of thermal power needed for standby & 0.2 & \\
\hline Time needed for power block startup & 0.5 & $\mathrm{hr}$ \\
\hline Fraction of thermal power needed for startup & 0.2 & \\
\hline Startup temperature & 400 & ${ }^{\circ} \mathrm{C}$ \\
\hline Maximum turbine over design operation fraction & 1.05 & \\
\hline Minimum turbine operation fraction before shutdown & 0.2 & \\
\hline
\end{tabular}

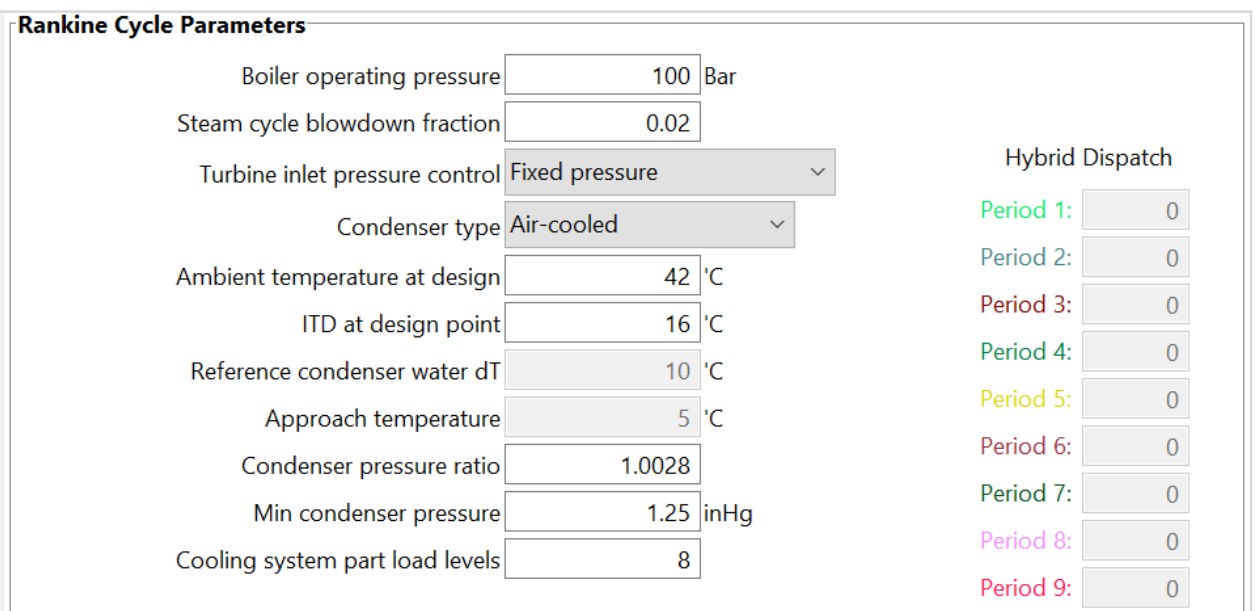

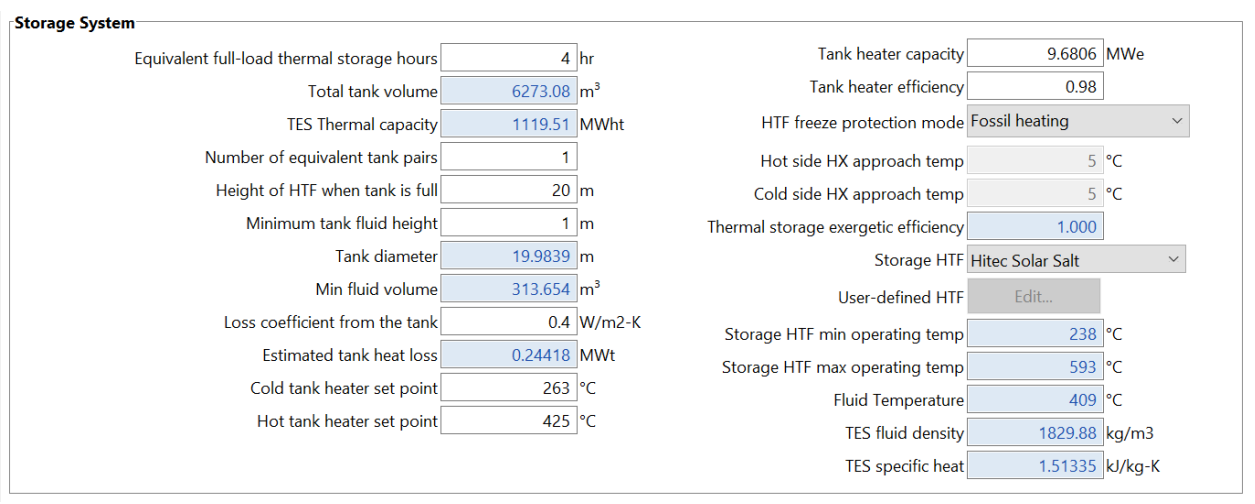

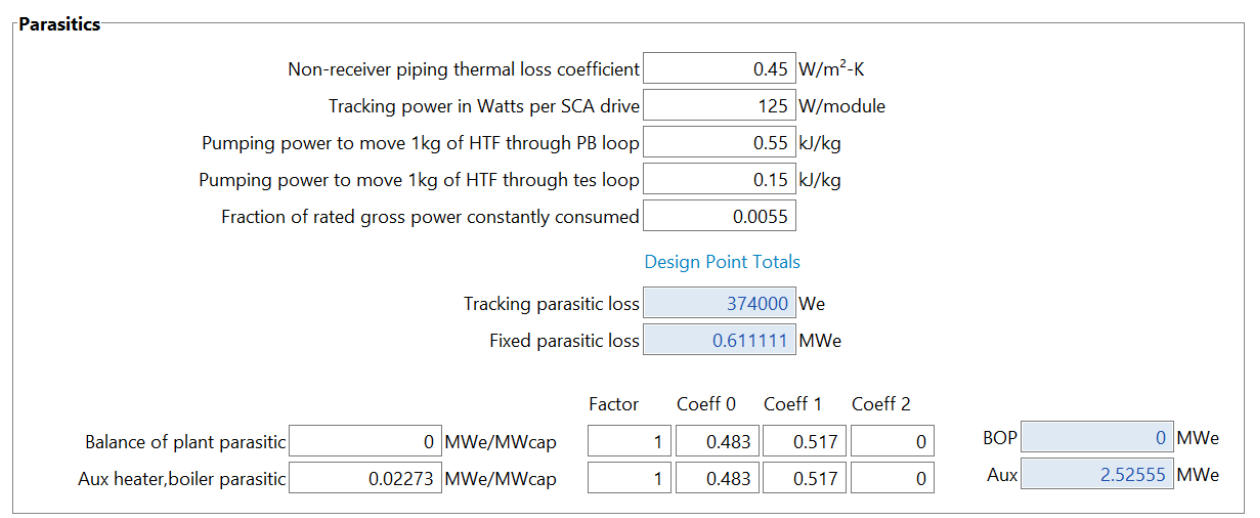




\section{REFERENCES}

[1] Sanderink, L., 2020. Shattered frames in global energy governance: Exploring fragmented interpretations among renewable energy institutions. Energy Research \& Social Science, 61, p.101355.

[2] Rashid, M.H., 2015. Electric Renewable Energy Systems. Academic Press.

[3] Murty, P., 2017. Chapter 24 - Renewable Energy Sources. In Electrical Power Systems, Elsevier.

[4] Viswanathan, B. 2016. Energy Sources. Elsevier.

[5] Kaushika, D. N., Mishra, A., \& Rai, A. K., 2018. Solar Photovoltaic System Design. Capital Publishing Company.

[6] Boretti, A., 2018. Concentrated Solar Power Plants Capacity Factors: A Review. Springer International Publishing

[7] Wagner, M.J., and Gilman, P., 2011. Technical manual for the SAM physical trough model (No. NREL/TP-5500-51825). National Renewable Energy Lab. (NREL), Golden, CO (United States).

[8] SEIA, 2020. Solar Industry Research Data. www.seia.org/solar-industry-research-data

[9] Solargis. 2019. Global direct normal irradiation. solargis.com/maps-and-gis-data/download/world

[10] GASTAT, 2018. Indicators of Renewable Energy in Saudi Arabia in 2018.www.stats.gov.sa/sites/default/files/indicators_of_ren ewable_energy_in_saudi_arabia_2017_en_2.pdf

[11] Solargis. 2019. Direct normal irradiation Saudi Arabia. solargis.com/maps-and-gis-data/download/saudi-arabia

[12] Almasoud, A.H. and Gandayh, H.M., 2015. Future of solar energy in Saudi Arabia. Journal of King Saud University-Engineering Sciences, 27(2), pp.153-157.

[13] Cau, G. and Cocco, D., 2014. Comparison of medium-size concentrating solar power plants based on parabolic trough and linear Fresnel collectors. Energy Procedia, 45(0), pp.101-110.

[14] Wagner, M.J., 2012. Results and comparison from the SAM linear Fresnel technology performance model (No. NREL/CP-5500-54758). National Renewable Energy Lab. (NREL), Golden, CO (United States).

[15] Morin, G., Karl, M., Mertins, M. and Selig, M., 2015. Molten salt as a heat transfer fluid in a linear fresnel collector-commercial application backed by demonstration. Energy Procedia, 69(Supplement C), pp.689-698.

[16] Wagner, M.J. and Zhu, G., 2011. Generic CSP Performance Model for NREL's System Advisor Model (No. NREL/CP-5500-52473). National Renewable Energy Lab.(NREL), Golden, CO (United States).

[17] Wagner, M.J. and Zhu, G., 2012, July. A direct-steam linear Fresnel performance model for NREL's system advisor model. In ASME 2012 6th International Conference on Energy Sustainability collocated with the ASME 2012 10th International Conference on Fuel Cell Science, Engineering and Technology (pp. 459-468). American Society of Mechanical Engineers Digital Collection.

[18] Neises, T., \& Boyd, M., 2018. Description of SAM's CSP User-defined Power Cycle Model: am.nrel.gov/images/web page files/Neises-DRAFT-user-defined-power-cycle-v3-2 018.pdf

[19] NREL, n.d., System Advisor Model (SAM). https://sam.nrel.gov/

[20] Weather atlas, 2020. Monthly weather forecast and climate Riyadh, Saudi Arabia. www.weather-atlas.com/en/saudi-ar abia/Riyadh -climate 